\title{
Performance Evaluation of Automatic Irrigation System under Three Different Depths of Placement of Sensor
}

\author{
S. S. Mane ${ }^{1 *}$, M. S. Mane ${ }^{2}$ and U. S. Kadam ${ }^{3}$ \\ ${ }^{1}$ Department of Civil Engineering, Indian Institute of Technology, Bombay, \\ Maharashtra, India \\ ${ }^{2}$ Interfaculty Irrigation Water Management, Post Graduate Institute, MPKV, Rahuri, India \\ ${ }^{3}$ Department of Irrigation and Drainage Engg., College of Agricultural Engineering and \\ Technology, Dapoli, India \\ *Corresponding author
}

\section{A B S T R A C T}

\begin{tabular}{|l|}
\hline Key w or d s \\
Irrigation \\
management, \\
Precision \\
agriculture, \\
Precision irrigation, \\
Soil moisture \\
\hline Article Info \\
\hline $\begin{array}{l}\text { Accepted: } \\
\text { 12 June } 2021 \\
\text { Available Online: } \\
\text { 10 July 2021 }\end{array}$ \\
\hline
\end{tabular}

The scarcity of water emphasizes the need of using irrigation water judiciously. The advance irrigation systems like drip and sprinkler irrigation etc. apply water accordingly. If one wants to apply water precisely, the criteria based on real time soil moisture can be used through which precision in irrigation can be achieved. Therefore, an attempt was made to design and develop the real time soil moisture based automatic irrigation system with GSM. However, study conducted by various scientists on performance evaluation of automatic irrigation system found that the depth of placement of sensor considerably affect the irrigation efficiencies. A very few scientists have worked on the appropriate depth of placement of soil moisture sensors. Therefore, the performance evaluation of an automatic irrigation system under three different depths i.e., $7.5 \mathrm{~cm}, 10 \mathrm{~cm}$ and $12.5 \mathrm{~cm}$ were carried out. The system was tested on cabbage crop. The biometric observation revealed that the crop under $7.5 \mathrm{~cm}$ depth of the sensor was superior over the other two depths with maximum water use efficiency. Further, it is revealed that the use of an automatic irrigation system with sensor placement at $7.5 \mathrm{~cm}$ depth was working efficiently and effectively along with saving water.

\section{Introduction}

In the context of climate change and the increasing population, there is a huge demand of food from the world and specifically from India. The total geographical area of India is 328.7 Mha out of which 200.9 Mha is the gross cropped area of the country $(61.11 \%$ of total geographical area). The net irrigated area is $68.2 \mathrm{Mha}$. The population of India is $16.5 \%$ (1.22 billion) of the world population and having only $4 \%$ of freshwater in the world (1). The increasing demand of water from water resources is growing due to the constantly rising population of India, industry, agricultural growth and other development. 
The supply of freshwater either remains more or less constant or decreasing. Therefore, there is a challenge to meet the ever-increasing demand of water from different stakeholders.

This situation emphasizes the need to use irrigation water judiciously. Irrigation plays a key role to increase per unite area productivity. In India, most of the farmers are practicing surface irrigation techniques such as border irrigation, check basin irrigation, furrow irrigation, etc. Farmers irrigate their field at the regular interval, which varies according to crop, soil and season. This method has several limitations such as over or under irrigation which create unfavorable environment for root development of plant. The unfavorable root environment stops the uptake of water and nutrient from soil which hampers the growth, ultimately reduces the yield (6). The advanced irrigation systems like drip and sprinkler irrigation etc. are used to overcome these limitations. The time-based irrigation system is used in most of the cases in which scheduling is tried on climatological approach. If one wants to apply water precisely, the real time soil moisture-based criteria can be used by which precision in irrigation can be achieved. Therefore, an attempt was made to develop a soil moisture based automated irrigation system for improving water productivity of crop.

In India, different companies have introduced their automatic irrigation systems. However, there are certain limitations to adopt the automatic irrigation systems on a farmer's field. Even after adopting the automatic irrigation system, it is difficult to understand whether that system delivers the right amount of water as per the requirement of the crop. Sometimes there is a possibility to under irrigate or over irrigate the fields by one or the other reason, which makes it difficult to maintain the moisture level of field always at field capacity in order to get better growth and yield along with saving water. However, study conducted by various scientists on performance evaluation of automatic irrigation system found that the depth of placement of sensor considerably affect the irrigation efficiencies (11). A very few scientists studied the appropriate depth of placement of sensors. Hence, there is a need to work more on this aspect to suggest the appropriate depth.

Therefore, considering the depth of soil, effective root zone of the crop under study and the research work done previously by various scientists three depths were selected i.e., 7.5 $\mathrm{cm}, 10 \mathrm{~cm}$ and $12.5 \mathrm{~cm}$. Hence, the present study entitled "Performance Evaluation of Automatic Irrigation System under Three Different Depths of Sensor" was undertaken at the Instructional Farm of Department of Irrigation and Drainage Engineering, College of Agricultural Engineering and Technology, Dr. BSKKV, Dapoli.

\section{Materials and Methods}

\section{Experimental site}

The automatic irrigation system at three different depths was tested at the Instructional Farm of Department of Irrigation and Drainage Engineering, College of Agricultural Engineering and Technology, Dr. Balasaheb Sawant Konkan Krishi Vidyapeeth, Dapoli (India). The experimental site is situated at $17045^{\prime} 12$ " N latitude and 73010 ' 48 " E longitudes and altitude of $250 \mathrm{~m}$. The location comes under the hot and humid climate region with an average annual rainfall of about 3542 $\mathrm{mm}$. The average minimum and maximum temperatures are $7.50 \mathrm{C}$ to $38.50 \mathrm{C}$, respectively. The relative humidity ranges from 46 to 99 percent. The soil was sandy clay with $\mathrm{pH} 6.5$ and lower nitrogen $(175.25 \mathrm{~kg}$. ha-1) and lower potash content (15.50 kg. ha1) and average in phosphorus content $(270.50$ $\mathrm{kg}$. ha-1). It was observed that the field 
capacity of the soil was 26.81 percent and the permanent wilting point was found to be 11.6 percent. Thus, the available moisture content was 15.18 percent. The bulk density of soil was observed as 1.40 g.cm-3 and the porosity of 47.04 percent. The basic infiltration rate was recorded as $6.27 \mathrm{~cm}$. hr-1 and hydraulic conductivity was $4.91 \mathrm{~cm}$. hr-1. Thus, it can be stated that this type of soil requires frequent but light irrigation (2).

\section{Experimental Details}

The developed automatic irrigation system was tested on the plot of $14.30 \mathrm{~m} \mathrm{x} 17.10 \mathrm{~m}$ for cabbage crop. The micro-sprinklers of 26 lph (liter per hour) discharge were installed at spacing of $1.5 \mathrm{~m} \times 1.5 \mathrm{~m}$. The cabbage crop was cultivated at spacing of $0.30 \mathrm{~m} \times 0.45 \mathrm{~m}$. The length and width of bed were 16 and $1 \mathrm{~m}$, respectively with $0.5 \mathrm{~m}$ pathway between two beds. The three soil moisture sensors i.e., SMS 1, SMS 2 and SMS 3 were installed in the field at the depth of $7.5 \mathrm{~cm}, 10 \mathrm{~cm}$ and 12.5 $\mathrm{cm}$, respectively as shown in Figure 1. The crop was irrigated with a micro sprinkler irrigation system. The micro-sprinklers of 26 lph discharge were installed at a spacing of 1.5 $\mathrm{m} \times 1.5 \mathrm{~m}$ as shown in Fig. 1. The recommended fertilizer dose of cabbage was used as 100:50:50 kg. ha-1 and the FYM (Farm Yard Manure) at 20 t. ha-1.

After proper bed preparation, the marking for transplantation was made by application of wooden stick with a spacing of $0.30 \mathrm{~m} \times 0.45$ $\mathrm{m}$. The plot was irrigated to its field capacity before transplanting so that seedlings could get favorable moisture conditions for settlement. $2 \mathrm{~g}$. L-1.

\section{Development of Automatic irrigation system}

The automatic irrigation system was developed at the Laboratory of Department of
Irrigation and Drainage Engineering, College of Agricultural Engineering and Technology, Dapoli (India) and the circuit diagram of designed automatic irrigation system is shown in Figure 2. The pictorial inner and outer view of the controller is shown in Figure 3.

The steps required for automation of irrigation system is explained in detail below. The first step for automation is to integrate smart phone / computer to the system for setting the predecided upper and lower set point for switch on/off the pump respectively. The soil moisture sensor is continuously sensing the moisture content in soil and sending the data towards the microcontroller. The microcontroller sends the signal to the relay to ON/OFF depending upon the soil moisture, which controls the solenoid valve and the pump. The text message intimates the user about solenoid valve and pump operation. The required programming is done in the Arduino IDE (7).

\section{Calibration of sensor}

The developed system was calibrated with gravimetric method. The gravimetric method for determination of the moisture content of the soil on a volumetric basis was used to know the accurate soil moisture content. Then, in the same soil, the sensors were inserted and kept for a particular time period to get stabilized voltage reading, which was then converted and calibrated as soil moisture content on a volumetric basis. Cobos and Chambers (3) has given the method of calibration of the sensor in detail, in which the voltage is recorded for the known percent of moisture. Using the regression equation, other values of voltage for the respective moisture content were estimated. The regression equation was written in programming language in the system. This will help to measure soil moisture content and apply irrigation on real time basis. 


\section{Depth of sensor}

The depth of placement of the sensors at a representative site play a key role to achieve higher irrigation efficiency. Similar study was reported by Soulies (11) on soil moisture sensor positioning considerably affect irrigation efficiency. The representative sensor reading was a key factor to provide more precise information about the average soil water condition at the root zone (10). The depth of placement of the sensor is the area where most of the active roots are present. Ryan et al., (9) reported that most of the active roots are nearer the surface where there is evaporation loss. Hence, it was necessary to fix the soil moisture sensor at a particular depth to sense available soil moisture content. Considering the depth of soil and the effective root zone depth of the crop under study, three depths were selected which were $7.5 \mathrm{~cm}, 10$ $\mathrm{cm}$ and $12.5 \mathrm{~cm}$. The close agreement in terms of depth of placement of sensor was found by several researchers during their studies as shown in the following Table 1.

Therefore, total three depths of placement of sensors were selected for installation in the field vertically at the depth of $7.5 \mathrm{~cm}, 10 \mathrm{~cm}$ and $12.5 \mathrm{~cm}$ for this study.

\section{Performance evaluation of sensors at three different depth}

The field performance evaluation and operation of the designed controller was carried out at Instructional Farm of Department of Irrigation and Drainage Engineering, College of Agricultural Engineering and Technology, Dapoli. The sensors were tested on field wherein the readout obtained from automatic irrigation system were compared with gravimetric method. The soil samples were randomly collected from the field and by using oven dry method its moisture content was determined.
The various biometric observations were recorded on five randomly selected plants of cabbage per bed. Labels were fixed on randomly selected cabbage plants for identification. The growth observation such as the height of the plant, number of leaves and coverage area of the plant were recorded at an interval of 15 days while the average weight of curd, the yield of cabbage, depth of water applied and time required to deliver the water and water use efficiency were recorded at the time of harvesting.

\section{Economic returns and B:C ratio}

Gross monetary returns per hectare were worked out by considering the curd yield and prevailing market prices for cabbage. The net income was estimated by subtracting the cost of production from gross monetary returns. Benefit-cost ratio was worked out by dividing the gross monetary returns to the cost of production. Rental value was considered as the fair market value of property while rented out in a lease. It was considered as 1/6th of the gross monetary returns. Interest on working capital was current liabilities subtracted from current assets. It was taken as $3 \%$ of the total variable cost. Payback period was computed as the ratio of initial investment to the cash inflows.

\section{Results and Discussion}

\section{Calibration of an automatic irrigation system}

From Table 2, it is revealed that when we add $0 \mathrm{~mL} /$ nil amount of water in $1000 \mathrm{~g}$ of oven dried soil, then the sensor readout was observed to be $1023 \mathrm{mV}$ and the soil moisture content by the gravimetric method was obtained as $0 \%$. When the amount of water is increased i.e., from 50 to $400 \mathrm{~mL}$ with an increment of $50 \mathrm{~mL}$, the sensors readout was observed to be decreased i.e., from $893 \mathrm{mV}$ to 
$218 \mathrm{mV}$, while the soil moisture content trend was observed to be increased from 5 to $40 \%$. Further, regarding field capacity which is $26.81 \%$, therefore from Table 2, it was observed that the soil is at field capacity when the amount of water between $250 \mathrm{ml}$ to $300 \mathrm{ml}$ in $1000 \mathrm{~g}$ of oven dried soil sample when the sensor readout is to be obtained as $483 \mathrm{mV}$ and $247 \mathrm{mV}$, respectively.

Further, from Table 2, it was observed that the moisture content in the oven dried soil was increased from 0 to 40 percent by adding 50, $100,150,200,250,300,350,400 \mathrm{~g}$ of water. The corresponding readouts were displayed on the computer screen in terms of millivolts. The readout approaches nearly close to field capacity between 25 to 30 percent moisture content, which is in close agreement as stated by Nallani \& Hency and Bowlekar (8),(2).

\section{Installation of sensor}

The representative sensor readings were a key factor to provide more precise information about the available soil moisture content at the root zone and further, it facilitates to $\mathrm{ON}$ and OFF the irrigation system automatically as per Lower Set Point and Higher Set Point (10). Considering the depth of soil and the effective root zone depth of the crop under study, the sensors were installed at $7.5 \mathrm{~cm}, 10 \mathrm{~cm}$ and $12.5 \mathrm{~cm}$ as shown in the Figure 5 to decide and judge further the appropriate depth of the sensor.

\section{Soil Moisture Dynamics in Experimental Plot}

The set programming of micro controller recording the data of soil moisture content at every two hours interval. The obtained data form soil moisture sensor was correlated with gravimetric method. These readings were presented in Figure 6 for the period from 20 to 22 February, 2019. It is very pertinent to note that as SMS-III was at $12.5 \mathrm{~cm}$ depth depicted $50 \%$ soil moisture depletion earlier than SMS-II and SMS-I, which is clearly indicates that at a deeper depth, the soil moisture content depletes quickly than the shorter depth (11). It is also very important to note that SMS-III when facilitated to ON system, it took maximum operational time i.e., $28 \mathrm{~min}$ followed by SMS-II (25 min) and minimum operational time was taken by SMS-I (20 min).

It can be concluded that as the soil moisture content is more or less similar in SMS-I at 7.5 $\mathrm{cm}$ and SMS-II at $10 \mathrm{~cm}$ depth and as the operational time is required less in SMS-I. Therefore, to save the water, energy without hampering the yield, the depth of sensor should be kept at $7.5 \mathrm{~cm}$ in the field.

\section{Field Testing of Automatic Irrigation system}

It is observed that the maximum per cent of growth of plant height was observed in SMS-I (7.5 cm depth of sensor) followed by SMS-II (10 $\mathrm{cm}$ depth of sensor), while minimum was observed in SMS-III (12.5 cm depth of sensor) as shown in figure 7 . From 60 DAT (day after transplanting) onwards, the plant height was observed to be stabilized which indicated that plants have diverted and utilized its complete energy to develop its curd. From Figure 9, the maximum percent increase in coverage area was found in SMS-I, while minimum in SMSIII right from 15 DAT to 75 DAT. Therefore, it is clearly indicated that SMS-1 provides congenial root environment for all the biometric observation in general and for plant spread in particular which resulted in more canopy area available for photosynthesis which again resulted in higher yield. 
Table.1 Depth of sensor used by researchers in their studies

\begin{tabular}{|c|c|c|c|}
\hline Sr. No. & Researcher & Year & Depth of placement of the sensor \\
\hline 1. & Kennedy et al., & 2003 & Sensors at $\mathbf{5}$ cm and $\mathbf{1 5}$ cm respond quickly \\
\hline 2. & Nallani and Hency & 2015 & $\mathbf{8} \mathbf{~ c m}$ \\
\hline 3. & Soulies et al., & 2015 & Most suitable position was $\mathbf{1 0}$ cm. \\
\hline 4. & Bowlekar & $\mathbf{2 0 1 7}$ & Two sensors used at $\mathbf{5}$ cm and $\mathbf{1 0}$ cm \\
\hline
\end{tabular}
((2), (5), (8), (11))

Table.2 Sensor readouts at a gravimetric moisture content

\begin{tabular}{|c|c|c|c|}
\hline Sr. No. & $\begin{array}{c}\text { Wt. of water added to } \\
\mathbf{1 0 0 0} \mathbf{g} \\
\text { oven-dried soil } \\
\text { sample (g) }\end{array}$ & $\begin{array}{c}\text { Moisture content } \\
(\mathbf{\%})\end{array}$ & Sensor Readout $(\mathbf{m V})$ \\
\hline $\mathbf{1 .}$ & 0 & & $\mathbf{1 0 2 3}$ \\
\hline $\mathbf{2 .}$ & 50 & 0 & $\mathbf{8 9 3}$ \\
\hline $\mathbf{3 .}$ & 100 & 5 & $\mathbf{8 2 1}$ \\
\hline $\mathbf{4 .}$ & 150 & 10 & $\mathbf{7 7 8}$ \\
\hline $\mathbf{5 .}$ & 200 & 15 & $\mathbf{5 8 3}$ \\
\hline $\mathbf{6 .}$ & 250 & 20 & $\mathbf{4 8 3}$ \\
\hline $\mathbf{7 .}$ & 300 & 25 & $\mathbf{2 4 7}$ \\
\hline $\mathbf{8 .}$ & 350 & 30 & $\mathbf{2 3 0}$ \\
\hline $\mathbf{9 .}$ & $\mathbf{4 0 0}$ & 35 & $\mathbf{2 1 8}$ \\
\hline
\end{tabular}

Fig.1 Layout of field

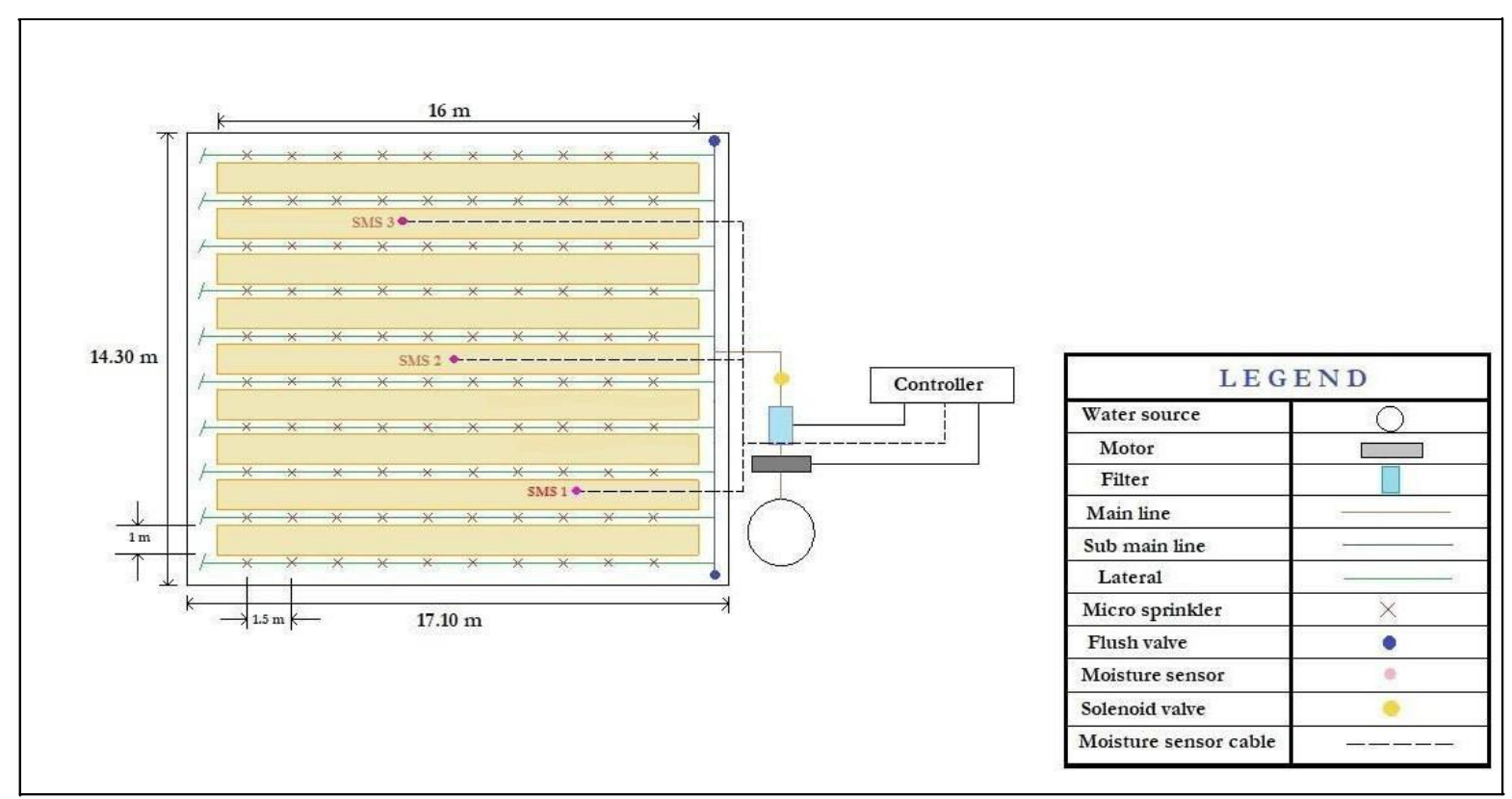


Fig.2 Circuit diagram

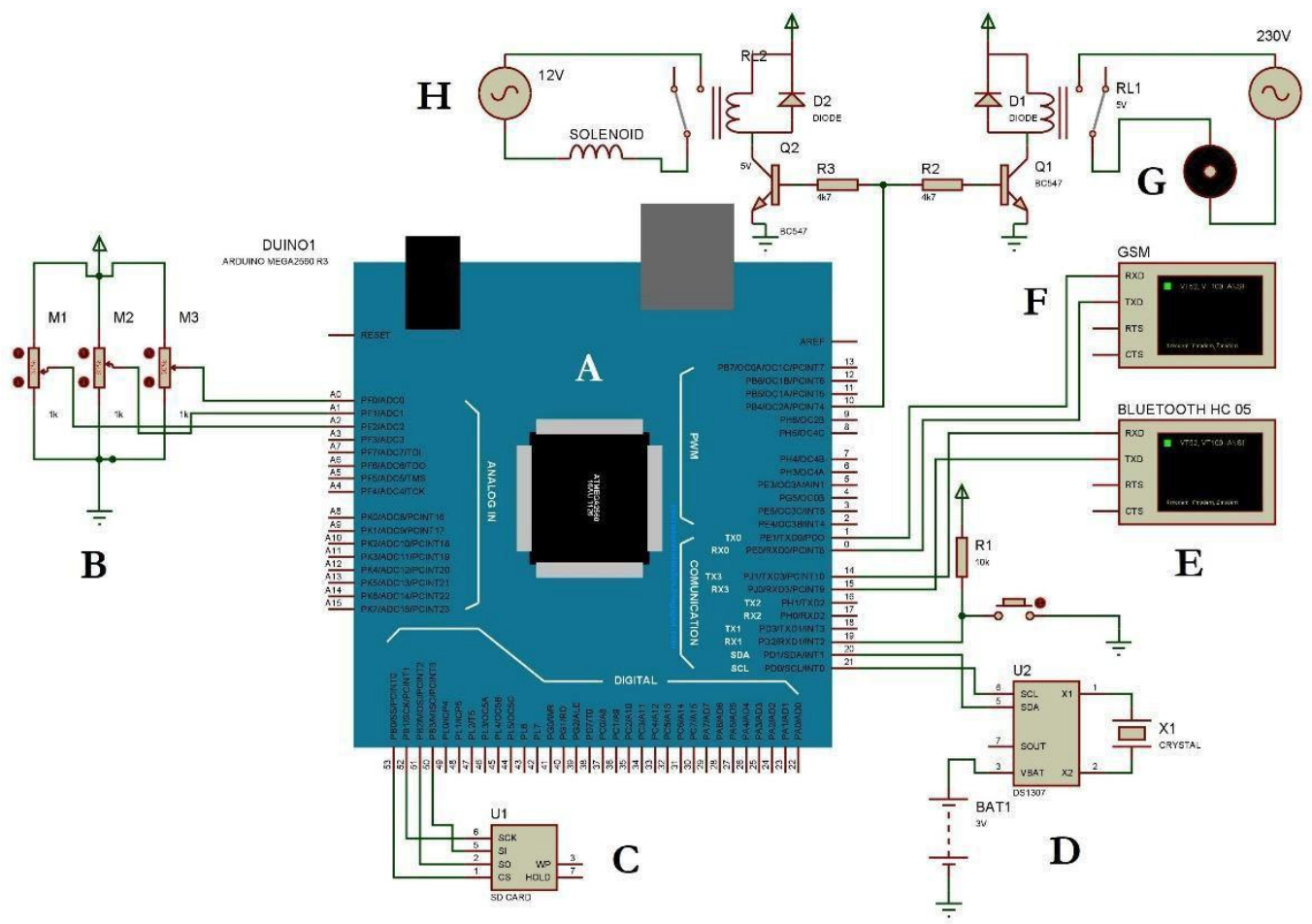

A- Arduino Mega Microcontroller, B- Soil moisture sensors, C- SD card module, D- Real time clock, EBluetooth module, F- GSM module, G- Pump, H- Solenoid valve

Fig.3 Inner and Outer view of the controller of an automatic irrigation system
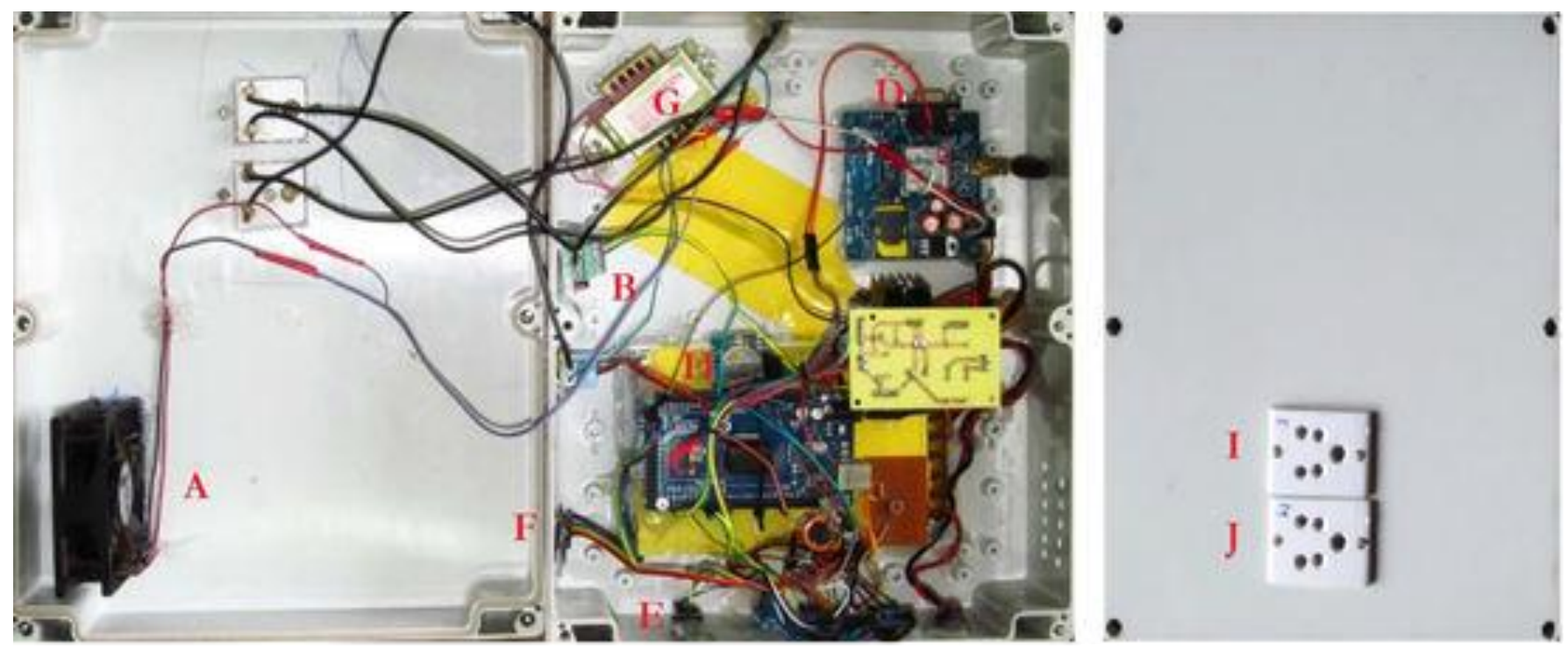

A- Fan, B- Relay, C- Arduino Mega, D- GSM module, E- Bluetooth module, F- SD card module, GTransformer, H- Real time clock, I- Socket for solenoid valve, J- Socket for pump 
Fig.4 Graph of sensor readout vs. Moisture content (\%)

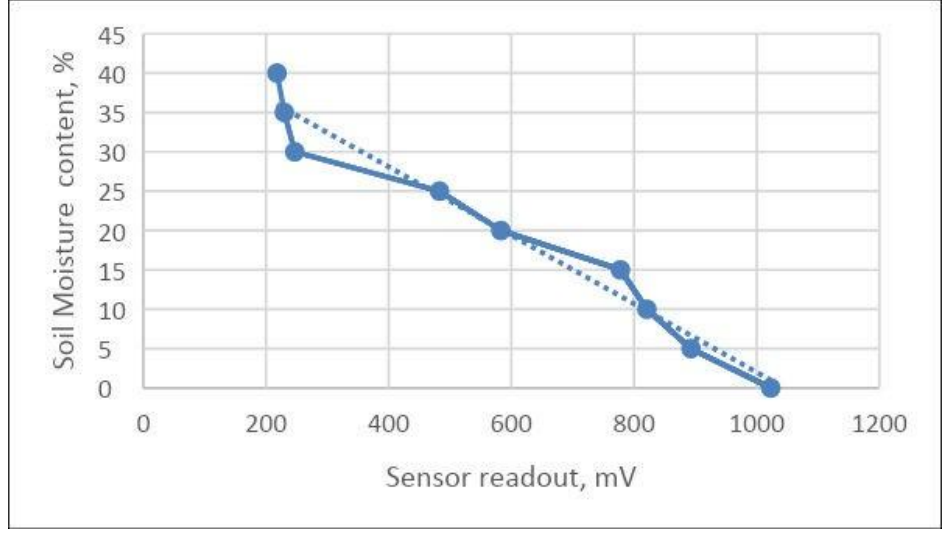

Fig.5 Sensors installed in the field

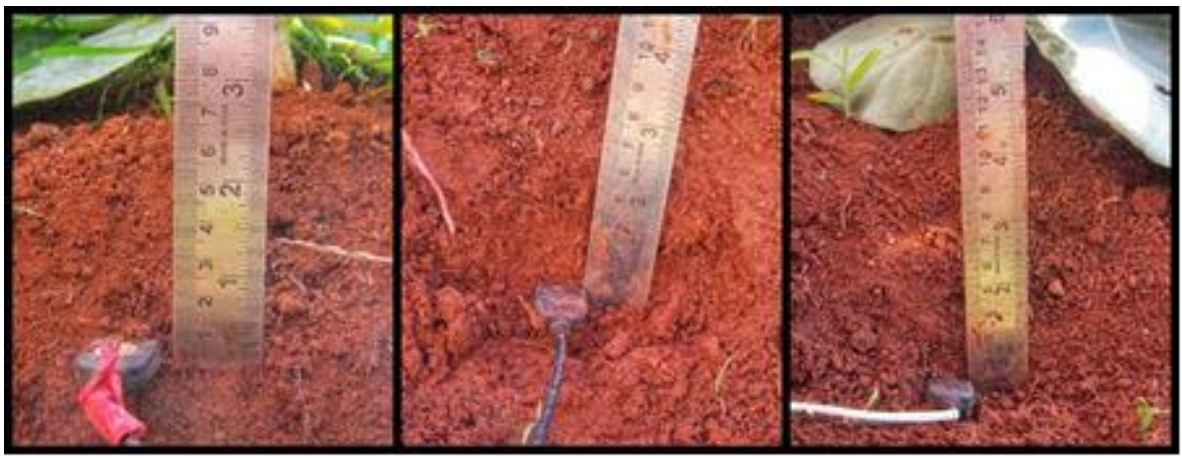

Fig.6 Field testing of sensors

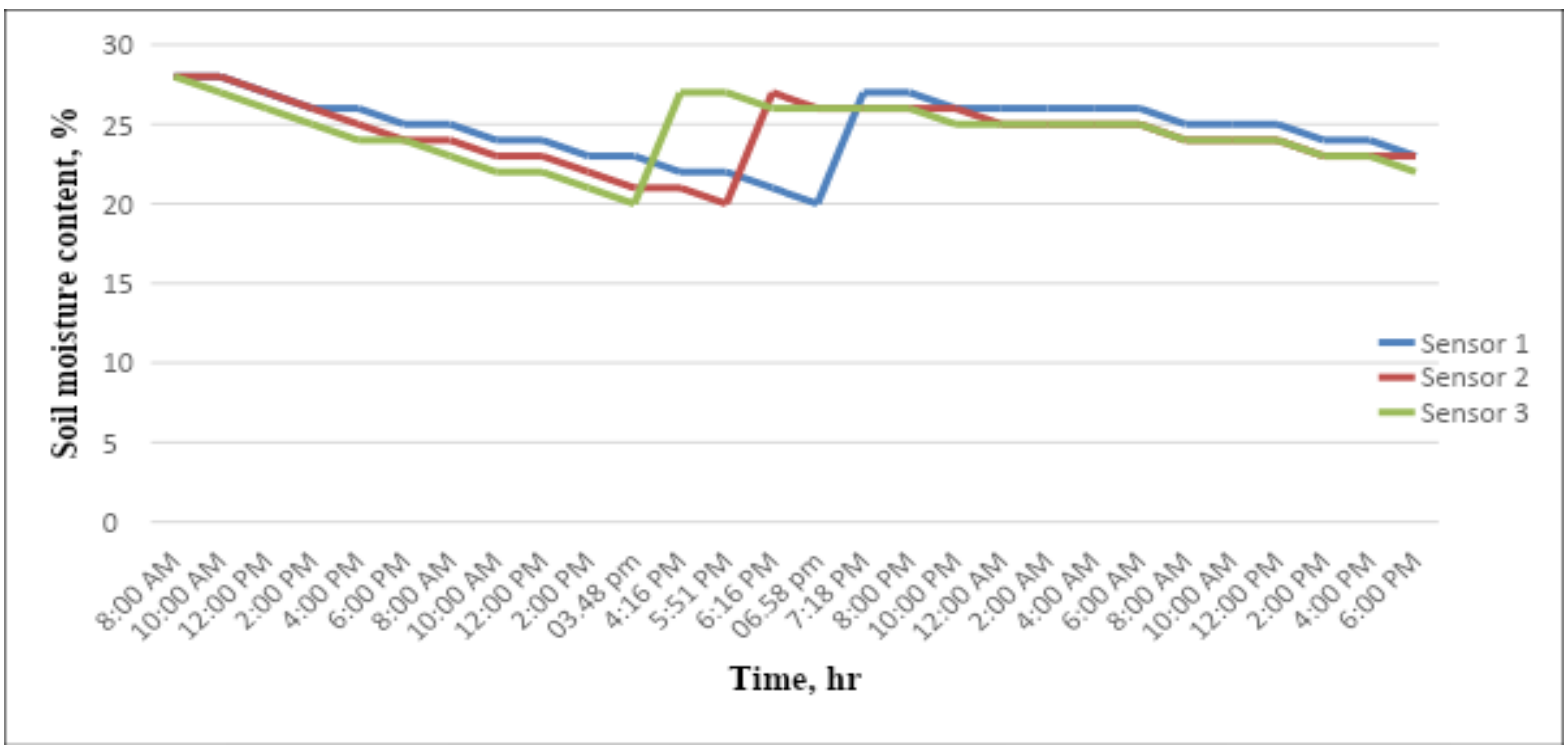


Fig.7 Effect of different depth of sensors on plant height

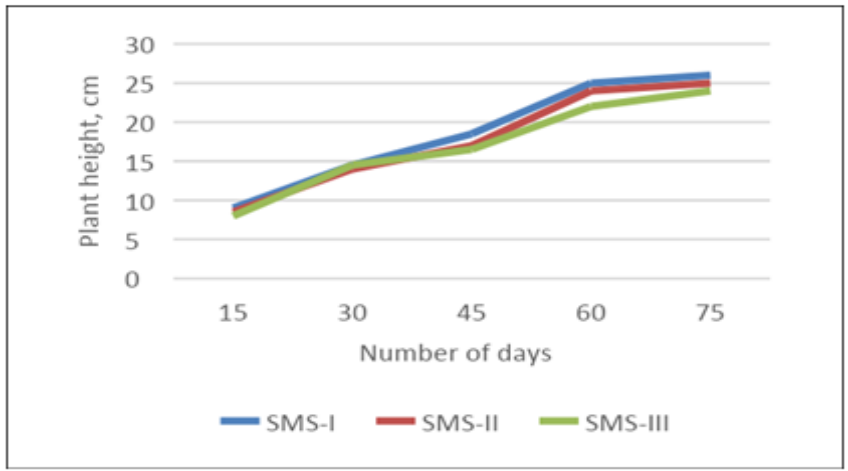

Fig.9 Effect of different depth of sensors on the spread area $\left(\mathrm{cm}^{2}\right)$

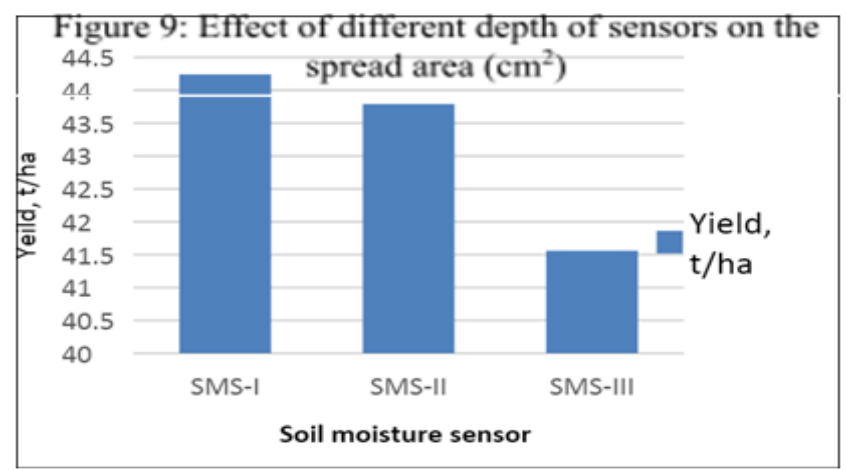

Fig.8 Effect of different depth of sensors on number of leaves

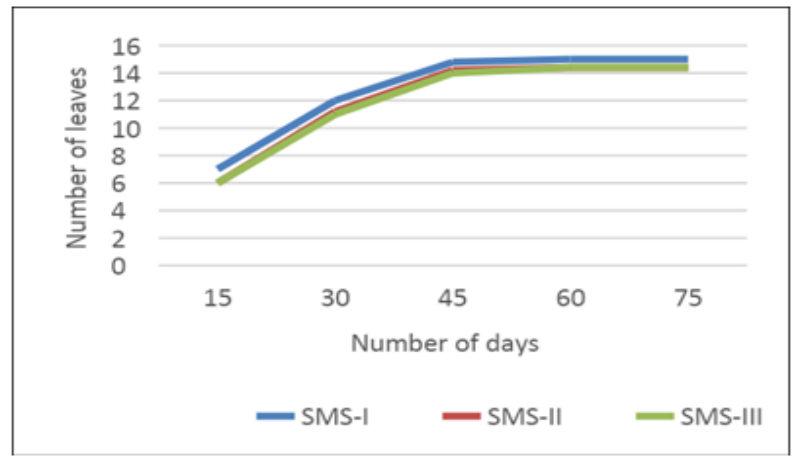

Fig.10 Effect of different depth of sensors on yield

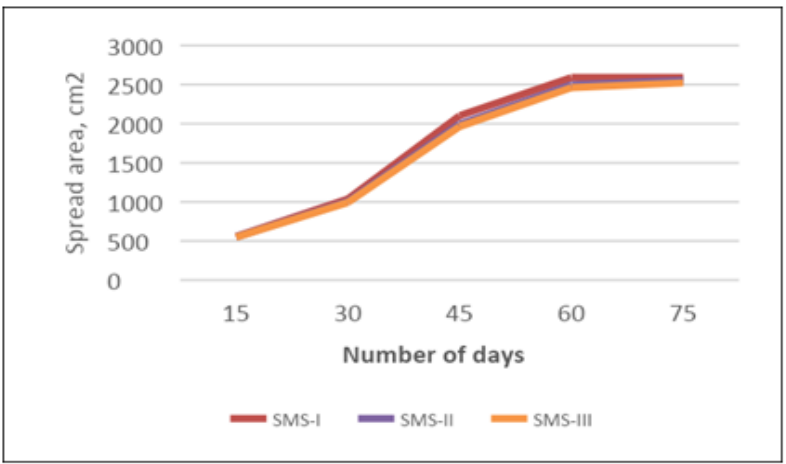

Fig.11 Depth of water applied and the time required to deliver water in three different sensors

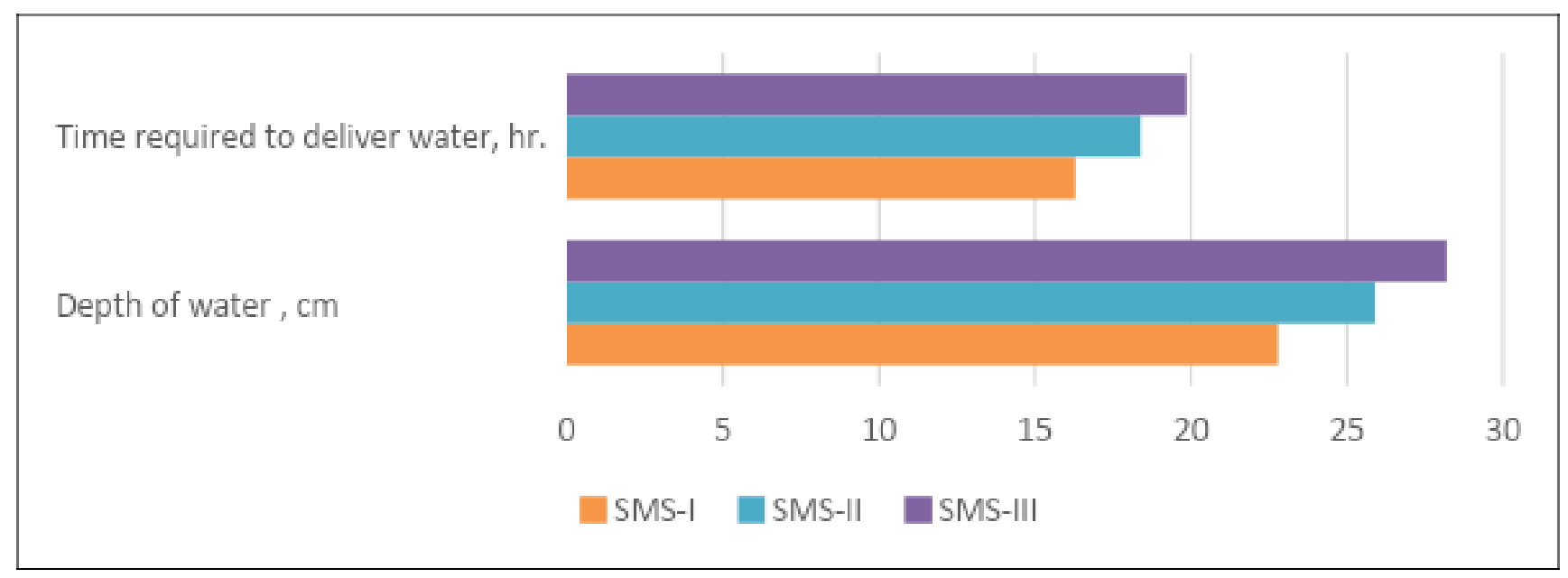


Fig.12 Water use efficiency in different depth of sensors

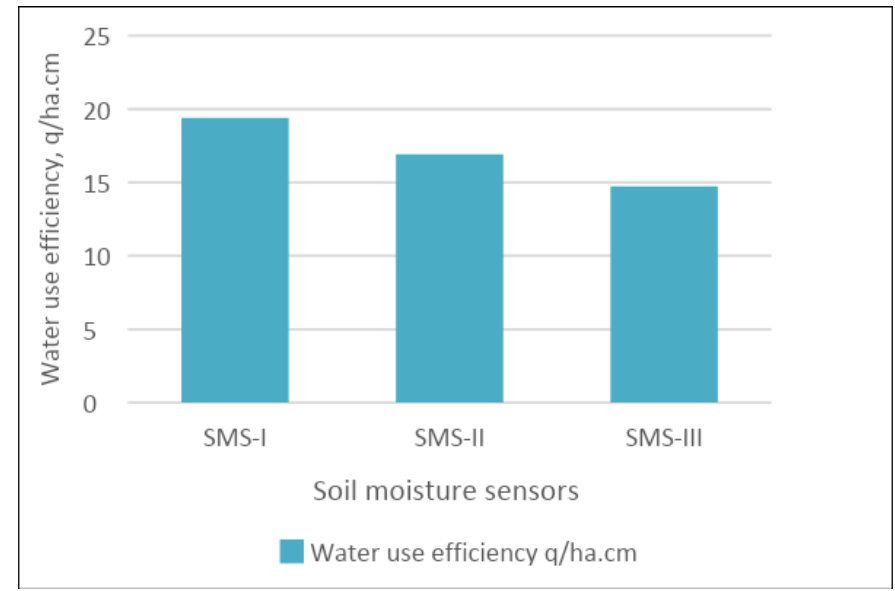

It is observed that the maximum and minimum average weight of curd was observed as 0.99 $\mathrm{kg}$ followed by $0.93 \mathrm{~kg}$ in SMS-I and SMS-III, respectively. It is revealed that the maximum average weight was observed in SMS-I.

From Figure 10, it was observed that the maximum average yield per ha was obtained in SMS-I as 44.24 tons which is slightly more than SMS-II (43.79 tons), while minimum average yield per ha was observed in SMS-III as 41.56 tons. The yield will be maximum when the root system absorbs more or optimum amount of nutrient and water (4). This can be achieved when the distribution of soil moisture is uniform in effective crop root zone. For the cabbage crop, the effective crop root zone is up to $10 \mathrm{~cm} \mathrm{(2),(6)} \mathrm{but} \mathrm{in} \mathrm{the}$ SMS-III, the sensor was placed at $12.5 \mathrm{~cm}$ depth from the ground surface. In such condition, due to the deeper depth, the soil moisture content might come up to LSP earlier than other two sensor depth i.e., $7.5 \mathrm{~cm}$ and 10 $\mathrm{cm}$.

It is interesting to note that when the soil moisture content at $12.5 \mathrm{~cm}$ is near to LSP at the same time in the above portion of soil from $12.5 \mathrm{~cm}$ is already in soil moisture stress condition.
Due to this reason, the plant roots were unable to absorb nutrient and water as effectively as in the other two conditions. This effect significantly affected the total yield as shown in Figure 10.

Depth of water applied and time required to deliver the water

From Figure 11, it was observed that the minimum depth of water applied over crop period was observed in SMS-I i.e., $22.80 \mathrm{~cm}$, while the maximum was observed in SMS-III i.e., $28.18 \mathrm{~cm}$ which clearly indicated that the increase in depth of water applied was due to the increase in depth of sensor from $7.5 \mathrm{~cm}$ to $12.5 \mathrm{~cm}$. The total time $24.11 \mathrm{hrs}$. were required to deliver the water as per the climatological approach. The time of operation was saved over climatological approach ranging from $32.47 \%$ to $21.52 \%$ in SMS-I to SMS-III. Therefore, it is revealed that the use of an automatic irrigation system with $7.5 \mathrm{~cm}$ depth of placement of the sensor is working efficiently and effectively for saving water and energy.

\section{Water Productivity}

Form Figure 12, it is revealed that the maximum water user efficiency was observed in SMS-I (19.40 q. ha-1. cm-1), followed by 
SMS-II (16.91 q. ha-1. cm-1), while minimum water use efficiency was observed in SMS-III as 14.74 q. ha- $1 . \mathrm{cm}-1$. This clearly indicates that due to the application of the right amount of water at the right place in the right time, the higher yield is attained.

\section{Cost analysis}

The total cost incurred for the design and development of the controller along with accessories is Rs. 11,330/-. Thus, the developed system is a low-cost system. From Table 4 , it is observed that the $\mathrm{B}: \mathrm{C}$ ratio is found to be maximum of the irrigation system with $7.5 \mathrm{~cm}$ sensor depth i.e., 2.32 followed by irrigation system with $10 \mathrm{~cm}$ depth of sensor i.e., 2.30 and minimum in irrigation system with $12.5 \mathrm{~cm}$ depth of sensor i.e., 2.23. The net income obtained in automatic irrigation system with $7.5 \mathrm{~cm}$ sensor depth is $9.75 \%$ more than the automatic irrigation system with $12 \mathrm{~cm}$ depth of sensor whereas for the sensor at depth $10 \mathrm{~cm}$ was found to be $8.10 \%$ more than the automatic irrigation system with $12 \mathrm{~cm}$ depth of the sensor.

The designed and developed automatic irrigation system works in any type of soil. This system takes care of and protects the crop to be grown in the field from moisture stress. Simultaneously it also takes care of not to exceed the soil moisture condition beyond field capacity. The performance of automatic irrigation system with $7.5 \mathrm{~cm}$ depth of sensor was found comparatively better in terms of attaining maximum yield and water use efficiency. The maximum B:C ratio 2.32 was observed in an automatic irrigation system with $7.5 \mathrm{~cm}$ depth of the sensor. The biometric parameters such as plant height, number of leaves and spread area and yield contributing parameters such as average weight of curd, the specific gravity of curd, yield tha- 1 and plant diameter was found maximum in automatic irrigation system with $7.5 \mathrm{~cm}$ depth of the sensor. The time of operation saved over climatological approach ranging from $32.47 \%$ to $21.52 \%$ in automatic irrigation system with a depth of sensor from $7.5 \mathrm{~cm}$ to $12.5 \mathrm{~cm}$. The automatic irrigation system with $7.5 \mathrm{~cm}, 10 \mathrm{~cm}$ and $12.5 \mathrm{~cm}$ saved $19.38 \%, 8.20 \%$, and 0.52 $\%$ volume of water, respectively over to be applied by the climatological approach. The system was designed and developed with the low cost i.e., Rs. 11,330/- (160 USD) per hectare.

\section{References}

1. Irrigation statistical year book India. Ministry of Statistic and Program Implantation, Government of India. 2017.

2. Bowlekar A. P. 2017. Design and Development of Low-Cost Automatic Irrigation System. M. Tech. thesis submitted to Dr. Balasaheb Sawant Kokan Krishi Vidyapeeth, Dapoli.

3. Cobos D. R. and C. Chambers. 2010. Calibrating ECH2O Soil Moisture Sensors. http://www.decagon.com//

4. Jackson L. E. 2005. Root Architecture and Growth. Encyclopedia of Soils in the Environment, 411-421.

5. Kennedy J., T. O. Keefer, G. B. Paige, and E. Barnes. 2003. Evaluation of dielectric constant-based soil moisture sensors in a semi-arid rangeland. Proceedings from the 1st Interagency Conference on Research in the Watersheds. Washington, DC: Consortium of Universities for the Advancement of Hydrologic Science, Inc. Pp. 503-508.

6. Lobet G., V. Couvreur, F. Meunier, M. Javaux and X. Draye. 2014. Plant water uptake in drying soils. Plant Physiology. Vol. 164: 1619-1627.

7. Mane SS, MS mane, US Kadam and ST Patil. 2019. Design and development of cost-effective real-time soil moisture based automatic irrigation system with GSM. International Research Journal of 
Engineering and Technology. Vol. 06: 1744-1751.

8. Nallani S. and V. B. Hency. 2015. Low Power Cost Effective Automatic Irrigation System. International Journal of Science and Technology. Vol. 8 (23).

9. Ryan P. R., E. Delhaize, M. Watt and A. E. Richardson. 2016. Plant roots: understanding structure and function in an ocean of complexity. Published by Oxford University Press on behalf of the Annals of Botany Company.118; 555-559.

10. Soulies K. X. and S. Elmaloglou. 2018. Optimum soil water content sensors placement for surface drip irrigation scheduling in layered soils. Computers and Electronics in Agriculture. Vol.52:1-8. https://doi.org/10.1016/j.compag.2018.06. 052

11. Soulies K. X., S. Elmaloglou and N. Dercas. 2015. Investigating the effects of soil moisture sensors positioning and accuracy on soil moisture-based drip irrigation scheduling systems. Agricultural Water Management. Vol. 148: 258-268. https://doi.org/10.1016/j.agwat.2014.10.01 5.

\section{How to cite this article:}

Mane, S. S., M. S. Mane and Kadam, U. S. 2021. Performance Evaluation of Automatic Irrigation System under Three Different Depths of Placement of Sensor. Int.J.Curr.Microbiol.App.Sci. 10(07): 170-181. doi: https://doi.org/10.20546/ijcmas.2021.1007.020 